\title{
La construcción del cuerpo del SIDA y sus estigmas
}

\author{
Augusto Claudio Obando Cid \\ Universidad de la Frontera. Temuco,Chile \\ Email:augusto.obando@ufrontera.cl \\ Olga Angélica Vásquez Palma \\ Universidad Católica de Temuco,Temuco,.Chile \\ Email:ovasquez@uct.cl
}

\begin{abstract}
Resumen: En este artículo se asume que el cuerpo excluido y sufriente es construido por la estructura social en connivencia con el sujeto y los colectivos que la componen. Aquellos que sufren no logran incluirse en el modelo impuesto, su ser es preso por una construcción cultural que lo limita. En Chile, en la década de los 80 - etapa de consolidación del modelo político-económico neoliberal- se inicia la construcción de un particular sujeto de peligro asociado a una pandemia mundial, que denominaremos el cuerpo del SIDA. Cuerpo objeto de sufrimiento y exclusión, que trasciende al enemigo interno terrorista, y cuya aparición fue posicionada en el márgen de la sociedad. El presente texto da cuenta de la construccion del cuerpo del SIDA y sus estigmas, a través de la revision de la prensa escrita, entre julio- agosto de 1984, cuando aparece el primer caso en Chile. El articulo explora la relación entre regímenes de visibilidad de los cuerpos en el contexto social, evidenciados en medios de comunicación y el discurso biomédico, exhibidos para aterrorizar y justificar su destrucción. Se describe el mercado del estigma y los alcances de la gestión del cuerpo terrorista en el contexto del capitalismo en clave neoliberal (biocapitalismo). Se evidencia la situación cotidiana de la violencia contra los cuerpos estigmatizados, negados e invisibilizados, expuestos solo para que la sociedad, conozca el terror de unirse a esos cuerpos que traen inscrita su aniquilación.
\end{abstract}

Palabras claves : SIDA; discursos; cuerpo; estigma.

\section{The construction of the body of AIDS and its stigmas}

\begin{abstract}
In this article it is assumed that the excluded and suffering body is constructed by the social structure in collusion with the subject and the groups that compose it. Those who suffer do not manage to include themselves in the imposed model, their being is imprisoned by a cultural construction that limits it. In Chile, in the 1980s -during the period of consolidation of the neo-liberal political and economic model- the construction of a particular subject of danger associated with a global pandemic began, which we call the body of AIDS. Body subject of suffering and exclusion; it transcends the internal terrorist enemy, and it whose appearance was positioned on the margin of society.This text gives account of the construction of AIDS body and its stigmas, through the revision of written press, between July-August 1984, when the first case in Chile appears. The article explores the relationship between regimes of visibility of bodies in the social context, evidenced in the media and by biomedical discourse, exhibited to terrorize and to justify their destruction. It is a description the market of stigma and the scope of the management of the terrorist body in the context of capitalism in a neoliberal key (biocapitalism). The daily situation of violence against stigmatized, denied and invisible bodies, exposed only only so that society knows the terror of joining those bodies that have their annihilation registered.
\end{abstract}

Keywords: AIDS; speeches; body; stigma.

\section{A construção do corpo da aids e seus estigmas}

Resumo: Neste artigo pressupõe-se que o corpo excluído e sofredor seja construído pela estrutura social em conluio com o sujeito e os grupos que o compõem. Quem sofre não consegue se incluir no modelo imposto, seu ser aprisionado por 
uma construção cultural que o limita. No Chile, na década de 1980 - durante o período de consolidação do modelo político e econômico neoliberal - começou a construção de um assunto particular de perigo associado a uma pandemia global, a que chamamos corpo de aids. Sujeito corporal de sofrimento e exclusão; transcende o inimigo terrorista interno e cuja aparência se posicionou à margem da sociedade. Este texto dá conta da construção do corpo da AIDS e seus estigmas, através da revisão da imprensa escrita, entre julho e agosto de 1984, quando o primeiro caso no Chile. O artigo explora a relação entre os regimes de visibilidade dos corpos no contexto social, evidenciados na mídia e pelo discurso biomédico, exibidos para aterrorizar e justificar sua destruição. É uma descrição do mercado do estigma e do escopo da gestão do corpo terrorista no contexto do capitalismo em uma chave neoliberal (biocapitalismo). A situação cotidiana da violência contra corpos estigmatizados, negados e invisíveis, exposta apenas para que a sociedade conheça o terror de se unir àqueles que têm sua aniquilação registrada.

Palavras-chave: AIDS; discursos; corpo; estigma.

\section{Inicios de la Epidemia, construcción del estigma}

«[E]l cuerpo está aprisionado en una serie de regímenes que lo atraviesan; está roto por los ritmos del trabajo, el reposo y las fiestas; está intoxicado por venenos — alimentos o valores, hábitos alimentarios y leyes morales todo junto; proporciona resistencias»

Michel Foucault.

«La guerra de este siglo es por el mundo interno.»

Adrián Scribano.

En torno al SIDA existe un consenso tácito, una producción de sentido que surge y se cristaliza como incuestionable e irrefutable en relación a su aparición, sus inicios, su posterior desarrollo y una representación social, que opera como una doxa hegemónica, generada a través de una discursividad social producida por múltiples agentes: la medicina, los medios de comunicación, los gobiernos, las entidades no gubernamentales, los individuos y las colectividades. Según la perspectiva de Verón, dicha discursividad social es concebida en términos del funcionamiento de la semiosis social, que debe entenderse como «la dimensión significante de los fenómenos sociales en tanto procesos de producción de sentido», (Verón, 1993, p.125). Estos explican el funcionamiento de los discursos en sociedad y dilucidan sus modos de generación, de recepción y de análisis, develando su circulación social y dan cuenta de la importancia que tiene la dimensión discursiva en la construcción social de la realidad.

La literatura señala que el SIDA aparece en el año 1981 en la ciudad de San Francisco, (Estado de California, Estados Unidos), donde los primeros casos son hombres jóvenes de clase media, pertenecientes a la comunidad gay, afectados por un raro cuadro patológico de características similares a las de personas que padecen enfermedades inmunológicas graves (Altman, 1981;MMWR, 1982). Sin embargo, con la aparición de nuevos casos en Estados Unidos y en Europa, se evidencia que la patología ya estaba presente en diversos países desde hace algún tiempo, antes del año 1981, cuestión que conduce a una alerta epidemiológica dada por la Organización Mundial de la Salud, (O.M.S), el Centro de Control de Enfermedades (CDC) en Atlanta y varios sistemas de salud de los países metropolitanos. El SIDA será establecido desde el discurso biomédico como la primera pandemia global producida en plena era antibiótica, cuyo referente histórico de comparación más cercano es la denominada «peste negra», una tragedia acaecida hace más de 400 años, que según registros históricos provocó la muerte de un tercio de la población de Europa. (NIH, 2005; Treichler, 1987).

Ante la novedad del fenómeno, la expectación y angustia de la sociedad, los medios de comunicación trabajarán incansablemente para reproducir y agudizar el alarma dada por los sistemas de salud, produciendo publicaciones y notas periodísticas que mezclan enunciados científicos, con estereotipos y prejuicios operantes en el sentido común (Sontag, 1996). Así, la discursividad social en torno al SIDA se nutrirá del conocimiento 
biomédico; para su producción en el campo social, se incorporará, además, el cruce entre diversos discursos políticos, económicos, religiosos, morales, informacionales y jurídicos. Con diversos énfasis de estos discursos, se construye un sentido común que rápidamente se propaga, generando una verdadera epidemia de significaciones (Treichler, 1987).

Esta forma de hegemonía discursiva comenzó a gestarse tempranamente desde la aparición de esta «nueva enfermedad», y a operar desde los primeros periodos de la patología como en su posterior desarrollo, lo que condujo a que fuera interpretada de diversas y equívocas maneras, generando estereotipos y procesos de estigmatización, que criminalizan a los sujetos afectados. En Chile la base de este discurso estaba ya siendo utlizado para todo sujeto que representara a una normalidad diferente a la del individuo ideal impuesto por la dictadura militar. El cuerpo del SIDA apareció en el momento en que se asentaba un modelo económico que construía una imagen de un país rico, moderno, sano, fuerte, ordenado y poderoso, digno de ser imitado, principalmente en su gobernanza. No cabía allí un cuerpo enfermo y contagioso, derivado de conductas inapropiadas, fuera del marco moral y político permitido, es un nuevo terrorismo que lleva en si mismo la destrucción.

De lo anterior, un ejemplo importante es que ante el desconocimiento del agente causal, se desplegarán variadas hipótesis que acusarán y responsabilizarán a los sujetos afectados por la enfermedad, señalando que el SIDA es producto de su promiscuidad y el uso de drogas recreativas. Expresiones como «terror biológico», «peste rosa», o «flagelo», se instalarán y cobrarán sentido en tanto nominaciones generadas por la discursividad social del SIDA y trasmitidas por diversas vías, estigmatizando a los sujetos nominados como los que portan las «4 H», (homosexuales, hemofílicos, heroinómanos y haitianos). Vale consignar, que se trata de personas que debido a la particularidad de cada uno de estos estigmas ya portaban un peso negativo -social y culturalmente construido-, que favoreció la cimentación de la culpa y el estigma. El cuerpo del SIDA vino a sumarse a una discriminación que ya los marcaba y que operaba en distintas prácticas sociales.

Por otra parte y en relación directa con esta discursividad social, como no había un diagnóstico claro, no se conocían las formas en que se trasmitía la infección, se desconocían los modos de prevención para no infectarse, se desconocía la existencia de algún tratamiento efectivo; el conocimiento biomédico se ubicó en el lugar central para la definición del SIDA como una entidad patológica, transformándolo en un objeto de análisis predilecto de las ciencias biomédicas, nominándolo y bautizándole como «Síndrome de Inmuno Deficiencia Adquirida». (NIH, 2005) ${ }^{1}$

No cabe duda sobre la fuerza que tiene el predominio del discurso biomédico en la doxa hegemonizada de la producción de sentido en torno al cuerpo del SIDA. Y que por lo tanto alejadas de la enfermedad, las ciencias sociales emprendieran tardíamente el cuestionamiento del discurso imperante y proponer investigaciones que pudieran debatir los presupuestos de la biomedicina y construir una crítica al sentido común que se había conformado. Entre estas investigaciones podemos destacar las de Altman (1986), Treichler (1987), Sontag (1996), Haraway (1995), Halperin (2002, 2007) y Dozon \& Fassin (1989); Fassin ( 2007); Fassin \& Rechtman (2009); Leclerc et al. (2000), sólo por nombrar algunas. Pero se trata de estudios provenientes de las Ciencias Sociales en el contexto metropolitano de Europa y de los países anglosajones. Son años en que hay escasa producción en América Latina respecto a la aparición del SIDA.

\section{Metodología}

En este estudio se realizó un análisis documental de los medios de prensa nacionales emitidos entre julio a septiembre de 1984, momento en que aparece el primer caso de persona que padece el Síndrome de Inmunodeficiencia Adquirida (SIDA) en Chile. Para entender el proceso de construccion del cuerpo del SIDAy sus estigmas, se realizó un análisis del discurso de estas fuentes de información.

El corpus analizado son las noticias, que en fotografías y discursos exponen la aparición del primer caso de SIDA en Chile, se identificaron elementos que dieron cuenta de la construcción del estigma y del establecimiento social del cuerpo del SIDA. 


\section{La construcción del estigma, la aparición del cuerpo del SIDA}

Según se observa en la figura 1, la interacción entre los discursos de la biomedicina, (representados por la investigación biomédica y el ministerio de salud), y la prensa escrita de la época, dan forma al proceso de estigmatización (Goffman, 2015) y puesta en escena del cuerpo del SIDA, en la sociedad chilena en plena dictadura cívico-militar.

Figura 1.

Formas de interacción entre los discursos de la biomedicina y de los medios de comunicación, en la producción de la estigmatización en el cuerpo del SIDA.

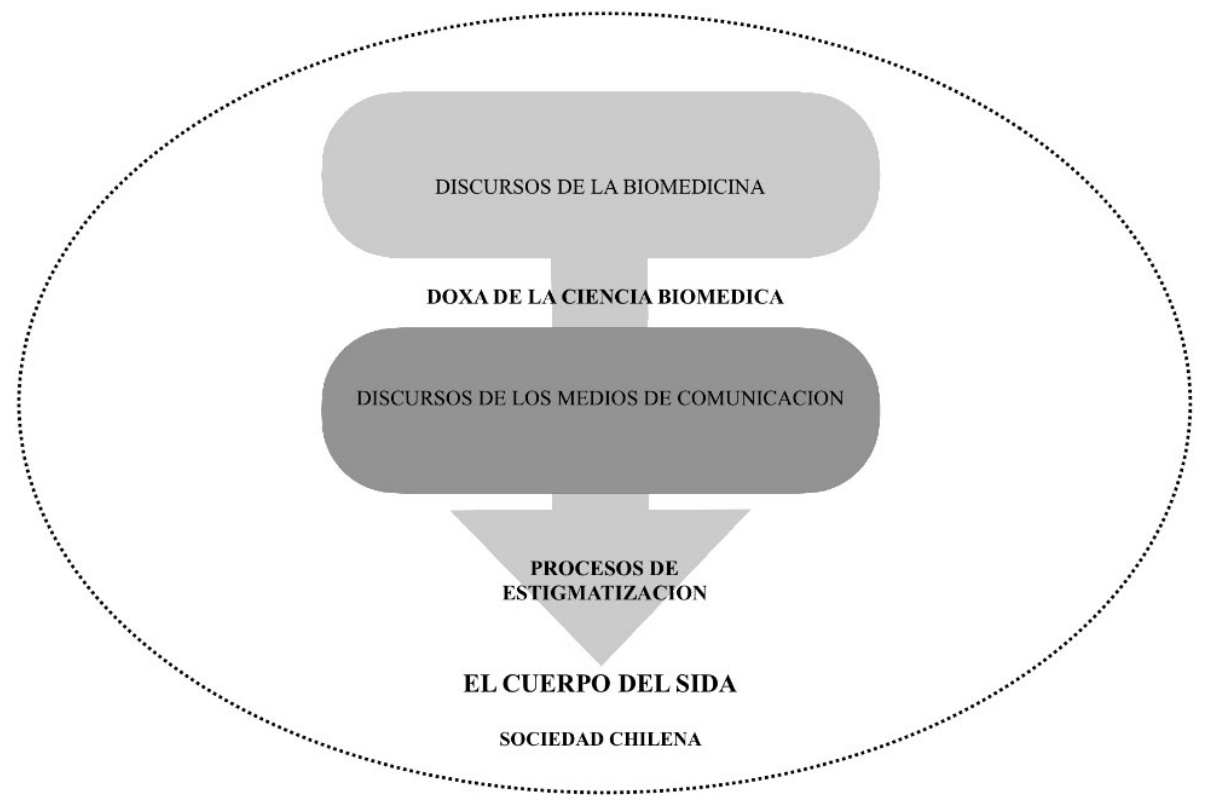

Fuente: Elaboración propia a partir del análisis del corpus investigativo.

La aparición del SIDA en Chile fue descrito a través de los medios de comunicación como un evento aislado, solo al producirse el fallecimiento del primer afectado, este ocupó la portada de dos diarios de circulación nacional - La tercera y Las Ultimas Noticias- los demás diarios presentaron la noticia y la opinión pública tuvo acceso a la información acerca de esta enfermedad, nueva y desconocida.

Dada las características de la enfermedad y el escaso conocimiento sobre ella, tanto a nivel internacional, como nacional, se generó la construcción del estigma y un proceso de estigmatización, sobre todos aquellos afectados por el SIDA, lo cual puede rastrearse en diversas fuentes como lo presenta la imagen 1. En ellas se instala un sentido en torno a la enfermedad con ciertas gramáticas de producción y de recepción, que construyeron los estigmas y el cuerpo del SIDA: Cancer «Gay», enfermedad «rara», donde el uso de las mismas comillas enmarca el hecho y el signo en una suerte de interrogación e inteligibilidad, pero que no son de fácil traducción, lo que generará más ignorancia, y en consecuencia la instalación del miedo y el estigma de lo intocable como parte fundamental de este sentido en torno a la imagen del cuerpo del SIDA.

En la producción del estigma sobre el cuerpo del SIDA, la imagen de la espalda del primer sujeto con SIDA en Chile, se transforma en ícono (Gilman, 1987), que por un lado muestra toda la magnitud del SIDA, pero que además sirve como espectacularización y estigma por otro (Altman, 1986). Es también la marca del cuerpo contagiado, de aquel que debe ser evitado y reconocido. 
Esta imagen fue utilizada por varios medios de prensa, siendo- La Tercera- quien la muestra reiteradamente en sus crónicas, tanto para describir la aparición como el fallecimiento del primer caso, con lo cual el cuerpo con las lesiones de Sarcoma de Kaposi se transforma en un objeto semiótico tanto para la biomedicina, como para los medios de comunicación. Desde la perspectiva de Bryan Turner (2008) puede entenderse como la anatomía política del cuerpo, donde los instrumentos de observación de la biomedicina, bajo su propia semiología fabrican al cuerpo. Por tal razón es necesario reescribir el texto del SIDA, teniendo en cuenta que: 1) la enfermedad es un lenguaje, 2) el cuerpo es una representación, 3) la medicina es una práctica política (Treichler, 1987; Turner, 2008)

\section{Imagen 1.}

Imágenes de la espalda del primer caso de SIDA en Chile y su uso por diferentes diarios -Portada de La Tercera, del 23 de agosto de 1984. Murió Paciente del Cáncer Gay chileno.
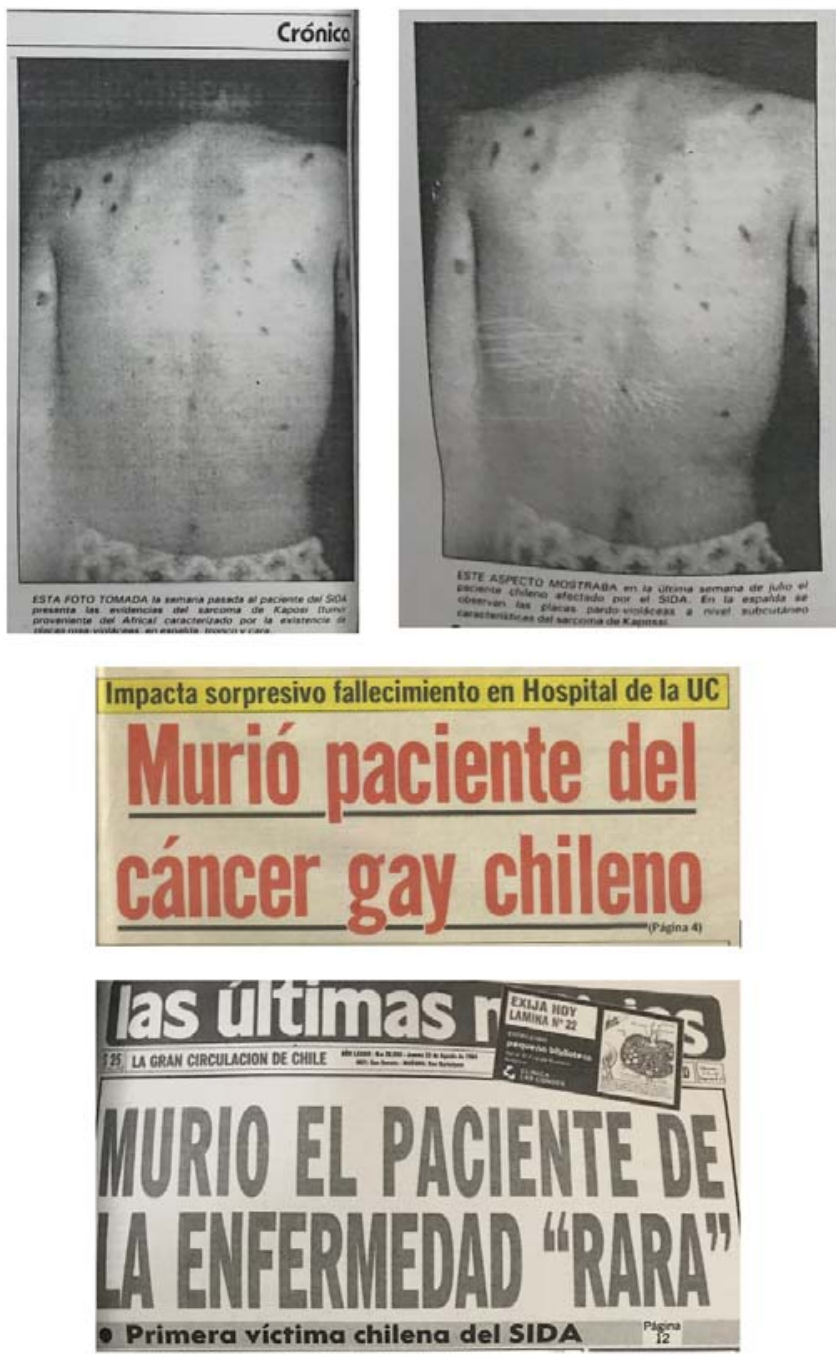

Fuente: Elaboración propia para la presente investigación con fuente La Tercera, Las Últimas Noticias, Julio- Agosto 1984

De lo anterior, según Haraway (1995), la experiencia de enfermar y de morir en lo general y de enfermar y morir de SIDA en lo particular; es un hecho social, constituido por numerosos procesos sociales heterogéneos. La autoridad cultural y material de las producciones biomédicas de cuerpos y de «yoes» es más vulnerable, más 
dinámico, más evasivo y más poderoso para ser tomado a la ligera y ser analizado descuidadamente (Haraway, 1995). Con ello el discurso biomédico, juega un papel tan preponderante como el discurso de la prensa, más aún, en esta producción de estigma en esta cadena productiva de discursos sociales (Verón, 2013).

\section{Cancer «gay»: aparición del primer caso de SIDA en Chile}

El evento fundante para la construcción del estigma y del cuerpo del SIDA en Chile, es la aparición del primer caso (ver figura 2). El cual se presenta a través de la prensa (La Tercera, 1 de agosto 1984) donde se hace mención del examen sanguíneo que confirma finalmente la presencia de la enfermedad en Chile, y se describe el complejo estado de salud que aqueja a V.R.R, con ello se da cuenta del primer caso de SIDA en Chile y el Ministerio de Salud (MINSAL) reconoce la existencia del cáncer «gay» en Chile.

La exposición de sus llagas y su cuerpo, evidenciando la presencia del sarcoma de Kaposi es una evidencia y marca de la patología, que da pie a la presencia no solo del dolor de vivir esa enfermedad, sino lo cruento del significado de padecerla, porque sólo la viven aquellos situados en la marginalidad por sus conductas. Ya no es una configuración de antecedentes clínicos, sino es un síndrome de vivencias y experiencias que presentan una connotación social de exclusión que genera sufrimiento. Así nace el cuerpo del SIDA.

Figura 2.

Aparición del primer caso de SIDA en Chile, Noticias: «Ministerio de Salud reconoce existencia de cáncer «gay» en Chile» - «Examen Sanguíneo detectó primer caso de SIDA en Chile»

LA TERCERA. 1 de agosto de 1984. Crónica

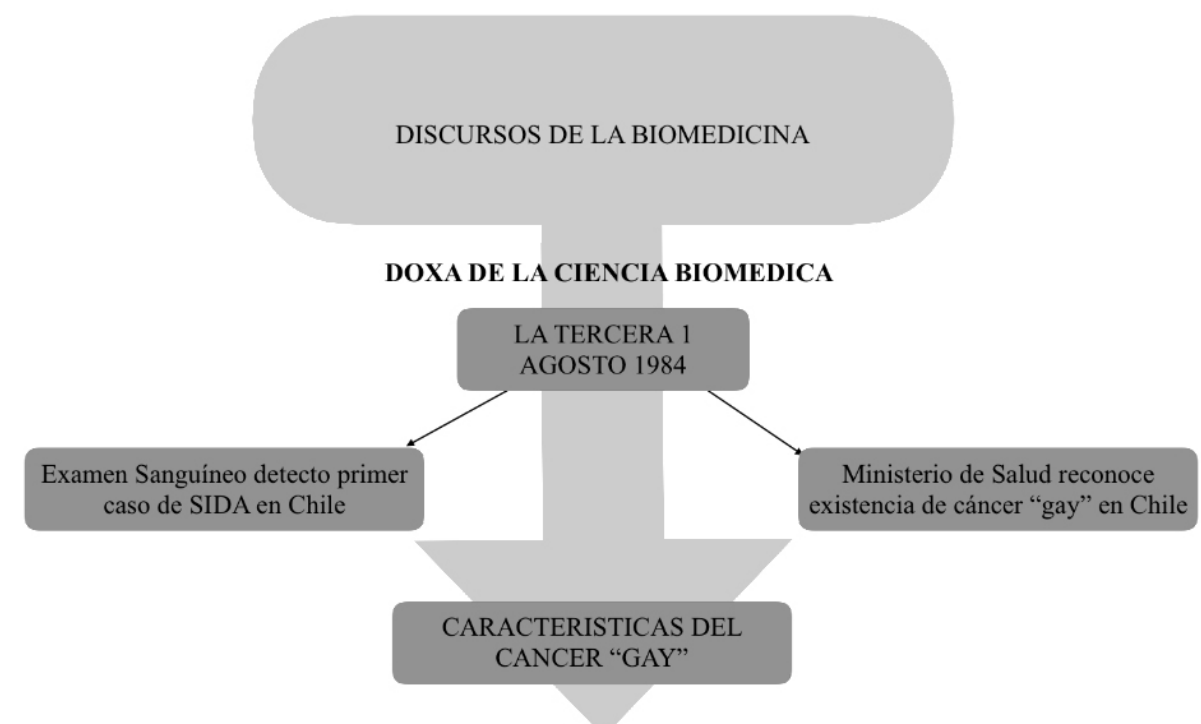

ESTIGMATIZACIÓN DE HOMOSEXUALES

EL CUERPO DEL SIDA

Fuente: Elaboración Propia a partir de «Ministerio de Salud reconoce existencia de cáncer «gay» en Chile»»Examen Sanguíneo detectó primer caso de SIDA en Chile» LA TERCERA. 1 de agosto de 1984. Crónica.

En el análisis de las noticias de la figura 2, el SIDA genera revuelo mundial, ante lo cual se presenta el primer caso comprobado de la enfermedad en Chile, identificado como V.R.R., de sexo masculino de 38 años, se plantea que se ha resguardado el diagnóstico, estado y evolución del paciente. Debido a que este caso reviste un alto valor clínico, epidemiológico y científico son variados los sujetos/agentes que deben ser informados de 
este, siendo relevantes el Ministerio de Salud (MINSAL), la comunidad médica, la comunidad científica y la opinión pública. Para ello existen vías específicas de información siendo particular en cada caso. Las Jornadas de Nuevas Patologías Infecciosas del Hospital Paula Jaraquemada, se utilizan para informar a la comunidad médica, la comunidad científica es informada gracias a la publicación de este caso en la Revista Médica de Chile y a la opinión pública se le informa a través de las noticias.

La información entregada tiene como finalidad generar alerta en la comunidad médica nacional; la prensa, por su parte, produce información de reconocimiento de un cuerpo que debe ser excluido por las marcas que son consecuencias de su conducta, y que, ante el desconocimiento de su forma de contagio, hay que aislarlo, ya que no solo contamina al cuerpo biológico, sino que acerca con fuerza al estigma social de la mala conducta que no se vincula a un delito, sino a una forma no aceptada de vivir la sexualidad, que es definida como rara, al igual que la enfermedad y el sujeto que la vivencia.

En el análisis de la noticia, se plantea, que con dicha información cada sujeto/agente realizará acciones específicas respecto del procedimiento diagnóstico, el tratamiento oportuno y las medidas preventivas, lo cual se profundiza en la noticia: «Ministerio de Salud reconoce existencia de cáncer «gay» en Chile» (La Tercera, 1 agosto 1984), donde se describe el rol del MINSAL en torno a la aparición de la nueva enfermedad, puntualizándose que el MINSAL, reconoce los casos, posee los medios para realizar el diagnóstico de la enfermedad, ha realizado acciones tendientes a enfrentarla, estableciendo la prevención, vigilancia, pesquisa y control del SIDA, a través de un programa de vigilancia epidemiológica, entregando la educación adecuada y la información sobre la magnitud oficial del SIDA en Chile. Se describe por último que se generará una comisión para analizar el problema del SIDA tanto medico/clínico, como epidemiológico.

Ciertas categorías se articulan en el proceso noticioso para generar el sentido sobre esta enfermedad en el contexto chileno. Aún cuando no se tiene claro el agente causal, y las vías de transmisión, el SIDA es una enfermedad de homosexuales, promiscuos, y donde la heterosexualidad esta exenta de riesgo, y con ello, la homosexualidad corre primero el peligro de infectarse y de infectar, por ello se les debe vigilar y controlar, a través de las herramientas que ya dispone el MINSAL.

La homosexualidad como categoría y signo, toma el eje central del discurso en las noticias, al parecer esta homosexualidad articula tanto la promiscuidad como vector de la infección, la drogadicción endovenosa, como así también, la problemática de la transfusión de sangre, con ello el homosexualismo es finalmente el agente causal, además el culpable de este explosivo contagio en Estados Unidos, ya que superponen en él todas las vías de contagio. Sin embargo, se aclara que, dado el tipo de homosexualidad que existe en Chile, es «personal» y no es una «patología social» como en Estados Unidos, estamos como país en un mejor escenario.

Ante el enunciado -Cáncer «gay»- por La Tercera (1 y 23 agosto de 1984), se debe explicar que la categoría «gay», que aún cuando en la actualidad es ampliamente usada y abusada, no era un vocablo de uso común en América Latina y en el mundo hispano hablante para referirse a la homosexualidad, hasta bien entrado la década de los 90 . No así, en la lengua anglosajona. El contexto en el cual emerge y es utilizada por la prensa de la década de los 80, es compleja de analizar y por ello es necesario un posicionamiento situado al respecto. Tal categoría tiene una genealogía particular en el contexto chileno, siendo esta la primera vez que se utiliza tal término en un medio de prensa escrito, como así mismo, es la primera vez que es utilizado en Chile de esta forma.

Lo relevante aquí es la aparición de esta categoría, cuando aun no se afianza o cristaliza otra categoría previa -la homosexualidad-. Esta última está referida específicamente a la psiquiatría del siglo XIX, que hizo emerger al perverso como un sujeto enfermo mental, un sujeto con el alma invertida (Foucault, 2005), sin embargo aquí, se usan como sinónimos, cosa que no es correcta.

El término «gay», puede rastrearse como categoría sexo-política en el contexto de la década de los 60 y en específico con los eventos de Stonewall de 1969, que permitió la emergencia del sujeto político y movimental conocido como movimiento gay y lesbiano, que posteriormente articuló la sigla LGBTIQA+, usada en la actualidad (Preciado, 2002). 
Con lo anteriormente descrito, en Chile en la década del 80 el uso del concepto gay esta completamente descontextualizado de las nominaciones existentes para señalar a la homosexualidad, recordando que esta última, solo es utilizada en el contexto de la medicina, ya que por ejemplo en el lenguaje jurídico se plantea el concepto de sodomía, pero que no es de uso común en la población; con ello se devela que las palabras cursan un posicionamiento de clase, ya que la población general, utiliza palabras peyorativas como «maricón», «fleto», «colipato», pero no homosexual, sodomita y menos gay.

Al parecer el concepto gay es traído por los medios de prensa desde el exterior, desde su uso en la lengua anglosajona y desde el contexto norteamericano, donde además, se dio a conocer la presencia de la enfermedad (Altman, 1981). Por ello el planteamiento de «cáncer gay» o cáncer «gay» entre comillas, por parte del periódico nacional La Tercera; es un préstamo/intercambio de las propias producciones de la prensa norteamericana donde el SIDA se presenta a través de la presencia del cáncer conocido como Sarcoma de Kaposi, pero lo interesante es el uso de lo «gay». Se tendrá que esperar hasta la década del 2000 recién en Chile, para que exista una traducción/recepción o en términos de Verón (1993; 2004; 2013), haya una gramática de la recepción para dicho signo.

El 8 de agosto en el diario La tercera (ver figura 3), se describe por un lado el estado de salud del primer caso y por otro las características más representativas de esta enfermedad, las cuales son homosexualidad y promiscuidad. En la noticia se refiere pormenorizadamente, la evolución del cuadro clínico del primer caso, que va desde su ingreso al centro de salud, por compromiso general y las lesiones físicas causadas por la inmunodeficiencia, se cuenta además con una imagen que será usada en varios medios de prensa (ver imagen 1), la cual es la espalda del sujeto, con lesiones por Sarcoma de Kaposi, donde se la describe como un cáncer que viene de África.

Figura 3.

Descripción y análisis de la aparición del primer caso de SIDA en Chile, Noticias: «Paciente chileno con SIDA tiene comprometido todo su cuerpo» - «Homosexuales Promiscuos están propensos a contraer síndrome» LA TERCERA. 8 de agosto de 1984. Crónica.

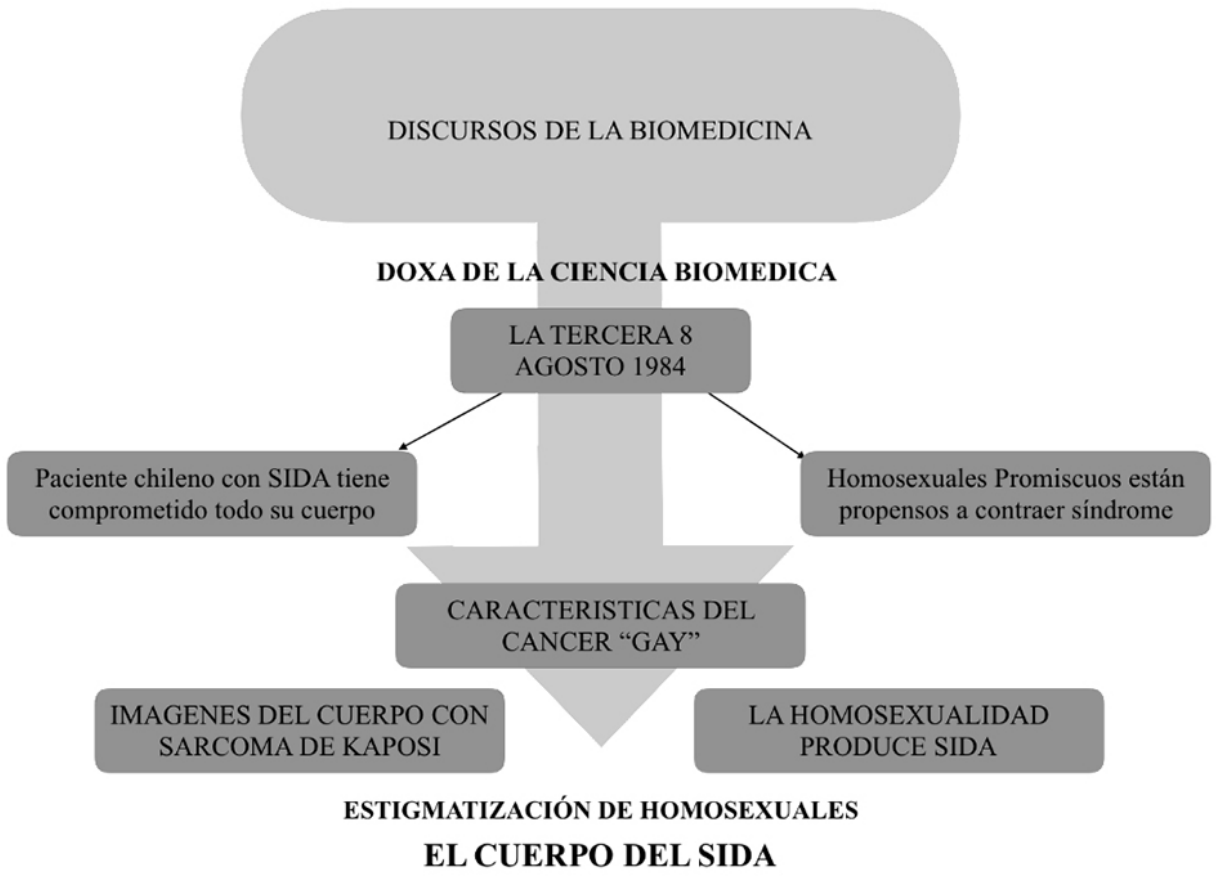

Fuente: Elaboración Propia a partir de «Paciente chileno con SIDA tiene comprometido todo su cuerpo» - «Homosexuales Promiscuos están propensos a contraer síndrome» LA TERCERA. 8 de agosto de 1984. Crónica. 
Otro aspecto relevante de la noticia es que se busca continuamente en ella de que el caso, cumpla con ciertos criterios para corroborar su infección con SIDA: su homosexualidad, los contactos sexuales en el extranjero, si tuvo contacto con haitianos, si era promiscuo. Se describe completamente el cuerpo afectado por la enfermedad, elaborándose una descripción pornográfica del estado de salud y deterioro corporal, para articular: SIDA, homosexualidad, promiscuidad y lesiones corporales (Sarcoma de Kaposi), en miras de establecer una norma para el contagio y una norma de conducta, que posteriormente derivará en el establecimiento del estigma (Goffman, 2015), del cuerpo del SIDA.

\section{El Mercurio no miente, construye estigmas}

El Mercurio el 2 de agosto de 1984, presenta al primer caso de SIDA en Chile; se desea puntualizar que las fuentes usadas por El Mercurio, son muy diferentes a las de los otros diarios, estableciéndose de esta forma que la misma producción de la noticia, está mediada con la clase y con las relaciones de poder como medio de prensa que apoya a la dictadura.

En la noticia es el mismo Ministro de Salud, Winston Chinchón Bunting -y no un comunicado- es quien presenta toda la información sobre el primer caso. (ver figura 4), con ello se devela un manejo de información bastante distinto a lo referido en otros medios de prensa, abre además la hipótesis de la colaboración directa de la dictadura con medios de inteligencia norteamericanos, lo cual se ve claramente en este caso, donde la cartera de salud declara que el agente causal es viral, es un retrovirus, que causa todo el síndrome de inmunodeficiencia. (Información que los demás medios de prensa no poseían).

La acción mas clara del MINSAL, fue transformar el decreto 169 de 1966 de Enfermedades Venéreas, con el Decreto 362, estableciendo así el Reglamento de Enfermedades de Transmisión Sexual con su modificación 294, que agrega SIDA a la lista de ETS. De esta forma el SIDA se estipula como una enfermedad de transmisión sexual, para utilizar los mecanismos que ya poseía el ministerio de salud contra la sífilis (venéreas), solo que ahora los reconfigura bajo la nueva perspectiva que la biomedicina realizará: a) vigilancia y control de la enfermedad, b) control de los casos, c) seguimiento de los afectados y un sin número de medidas policiacas, que según relata el mismo ministro «se tenían ya previstas esperando la aparición de la enfermedad entre homosexuales» (El Mercurio, 2 de agosto 1984).

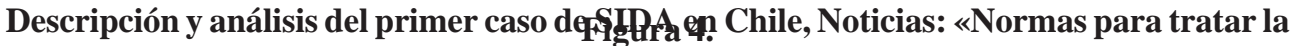 inmunodeficiencia» EI Mercurio. 2 de agosto de 1984. Crónica. «SIDA provoca fiebre y baja en peso físico» El Mercurio. 5 de agosto de 1984. Crónica. «EI SIDA no tiene aún importancia en Chile» El Mercurio. 10 de agosto de 1984. Crónica.}

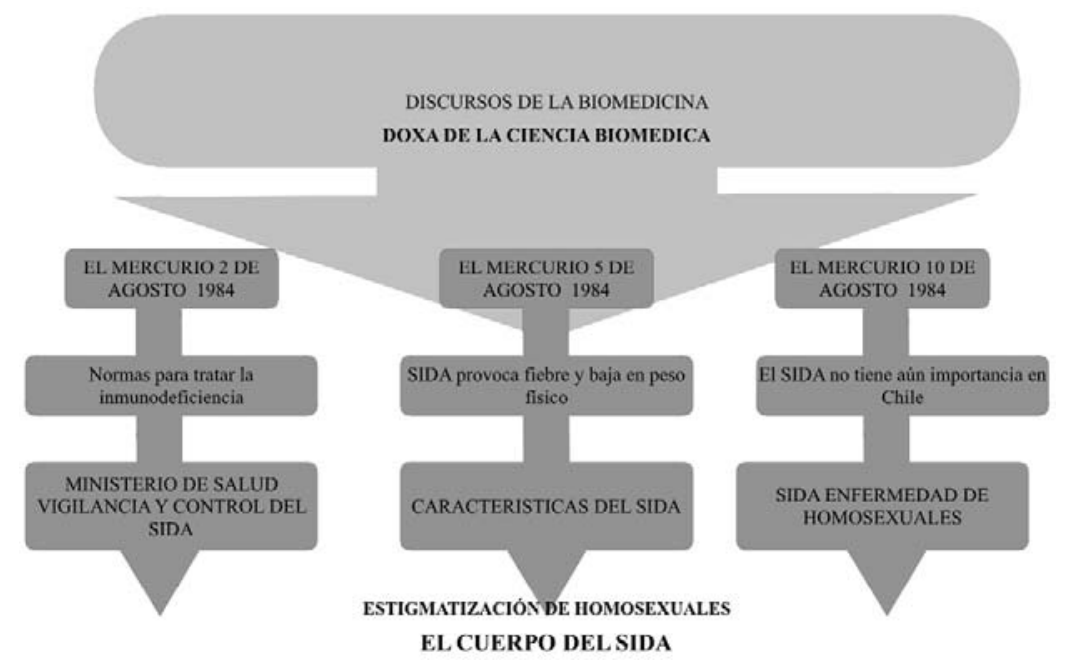

Fuente: Elaboración propia a partir de El Mercurio. 2 de agosto de 1984; 5 de agosto de 1984; 10 de agosto de 1984. Crónica. 
El diario El Mercurio, al igual que La Tercera, presenta el primer caso del cuerpo del SIDA, y su evolución en relación al estado de salud de este. Aquí la entrevista no es un comunicado emanado del centro de salud, sino es la entrevista con el equipo médico que esta encargado de la atención directa del caso, que describen pormenorizadamente las principales características de la evolución del cuadro, desde una perspectiva pornográfica, solo que esta vez el lenguaje es altamente biomédico, planteándose la necesidad de traducirlo para la recepción del lector (ver figura 4).

Continuando con la presentación del caso por El Mercurio (ver figura 4), se entrevista a un especialista estadounidense Dr. Donald Louria, que participa de las Jornadas de Nuevas Patologías Infecciosas del Hospital Paula Jaraquemada, donde fue presentado el primer caso detectado de SIDA en Chile. Este plantea la similitud del caso chileno, con el caso de Estados Unidos, además de plantear que este síndrome es detectado en población homosexual, colocando de manifiesto que, dada la incidencia, no debería plantearse como un problema grave para la Salud Publica en Chile, esto debido a que los afectados son homosexuales, por tanto, sobre ellos hay que localizar la vigilancia.

Este correlato entre el SIDA chileno y estadounidense, plantea como eje en común y articulador a la homosexualidad, que debe analizarse en relación a la promiscuidad y además a la donación de sangre. A momentos parece encontrarse en estos discursos, lo planteado por Foucault en lo referente a la «simbólica de la sangre y analítica de la sexualidad» (Foucault, 2005, p.179), solo que en vez de referirse a la preocupación de la sangre como linaje, es la preocupación de esta como flujo viviente y como tejido vital para la donación y transfusión en la nueva gramática de la biomedicina, del cuerpo del SIDA, que contiene un relato de terror al contagio, debido a que todo lo que emerja de los homosexuales debe ser puesto en vigilancia. Como lo es el cuerpo de los pobres, el cuerpo indígena, el cuerpo de las mujeres, el de los militantes upelientos; son cuerpos renegados, marginados, excluidos. Es el gran cuerpo sufriente, pero rebelde sólo porque existe. El cuerpo del SIDA comienza a ser constituyente del cuerpo terrorista, el enemigo interno de la dictadura.

En la noticia se describe que aun cuando no hay contaminación en la sangre de reclusos, se percibe en el discurso del médico, de que pronto aparecerá la contaminación, que es solo cosa de tiempo; debiendo tomarse medidas apenas se observe la contaminación de prohibir a homosexuales a donar sangre. Con ello sangre y sexo/ semen, se contaminan ante la presencia corrupta de la homosexualidad. Nuevamente la Sciencia Sexualis (Foucault, 2005) en una nueva reconfiguración, pone al homosexual en el centro de la contaminación, del contagio, donde entendida como "patología social» (El mercurio, 10 de agosto de 1984) que tarde o temprano acabará con enfermar a todo el cuerpo social.

En el caso del cuerpo del SIDA, se está en presencia del paradigma de la transgresión de todas las leyes existentes (desde la perspectiva del sentido común y la doxa); solo que hoy la biomedicina y su gestión de los cuerpos «infectados» del VIH/SIDA, plantea una reconversión de esta transgresión, desde la norma religiosa (puro/impuro) y de la norma biomédica clásica (normal/anormal), a la norma microbiológica (contagiado-infectado/ sano), y por último del tipo inmunitario (contaminado-riesgoso/ posible afectado) (Cadahia, 2014;Esposito, 2005, 2006, 2009). No es que se hayan superado del todo las anteriores transgresiones (religiosas y biomédicas), sino que estas entran en un juego de solapamientos y superposiciones, de estas últimas con las primeras.

Lo anterior permitió que en la dictadura, en el periodo de asentamiento del modelo político-económico neoliberal, el cuerpo del SIDA pasará a constituir parte del cuerpo del terrorista, antes Foucault (2005) en «La voluntad de saber» lo incluyó en la lucha de clases, (burguesía contra la aristocracia), entre la analítica de la sexualidad y la simbólica de la sangre.

Por tanto a través del «dispositivo sexualidad» (Foucault, 2005) y las «tecnologías de género» (Lauretis, 1989), se dio materialidad a este cuerpo, solo que en la actualidad (gracias al vitalismo organicista que engendra a la biomedicina) este ha devenido en organismo, y todo organismo es máquina; los organismos/órganos son los enemigos del cuerpo (Deleuze \& Guattari, 1985), un organismo con miembros, con multiplicidad de órganos, tejidos, células y moléculas. Cada nivel anterior deviene foco de gobierno, objeto de formas nuevas de autoridad y conocimiento especializado, campo intensamente caracterizado de conocimiento, territorio en expansión para la explotación bioeconómica, principio organizador de la ética y eje de una política vital molecular (Rose, 2012 ). 


\title{
El mercado del estigma: ética somática y el espíritu del biocapitalismo
}

\author{
«Es posible decir que existe una afinidad electiva entre la ética somática contemporánea y el espíritu del \\ Biocapitalismo.» \\ Nikolas Rose, Políticas de la Vida.
}

Los medios de comunicación posicionan al cuerpo terrorista, al cuerpo del SIDA fuera de la normalidad construida desde el discurso hegemónico, en que lo diferente resulta sumamente peligroso. Con el cuerpo del SIDA ya no necesitas armamento externo para inducir terror a la población, no necesitas construir un discurso de político, como el terrorista de izquierda. Su sola presencia incita al terror, como lo es el cuerpo indígena cuya genética contamina y destruye la estética blanca, como lo es el cuerpo de la mujer al que hay que reducir porque trasgrede la moral. Esto hace necesario regresar a Goffman y a la noción de «ser humano normal», que según este autor tendría un posible doble origen, el primero en el enfoque médico de la humanidad y el segundo en las instituciones del Estado-Nación, que tratan, en ciertos aspectos a los individuos como iguales. (Goffman, 2015).

El estatuto de normalidad, posee una doble posibilidad de estigmatización, debido al juego de ambas dimensiones (biomédica/igualitaria), además estas dan la posibilidad de generar un entramado más complejo en los procesos de interacción; siendo posibles múltiples formas de estigmatizaciones (auto, inter, intra, co). Culminando en una contaminación identitaria (Goffman, 2015), y cuando se plantea el estigma al nivel de la contaminación, operando de formas múltiples, contingentes y radicales, se puede concluir, trastocando los postulados goffmanianos, que es finalmente no es el cuerpo quien porta un estigma, sino más bien, el estigma es lo que construye al cuerpo, como entidad material molar y molecular.

Se debe dejar en claro que, aún cuando el estigma es de antigua data en lo concerniente a su historicidad, es sólo a partir de la configuración de la modernidad y de los adelantos de la medicina, que éste pudo ser de alguna forma «tratado». Pero no es hasta las profundas transformaciones del capitalismo del siglo XX y los avances de la Biomedicina, de que, en la actualidad, el estigma devino productividad y por ende con la posibilidad cierta de transformarse en mercancía. Ya que como describe Goffman (2015), al parecer existe desde hace algún tiempo un mercado para el estigma, uno de la readecuación corporal, del rediseño y re ensamblaje; usándose metáforas de la fábrica. Pero además hoy el lugar paradigmático de la producción postfordista, más allá de fábrica, es el laboratorio. Donde se genera un circuito virtuoso entre ellos, ya que no se sabe con claridad donde inicia el laboratorio y donde acaba la fábrica.

Al parecer, hoy es factible la fabricación/producción del «ser humano normal»; las políticas de los sentidos, nutricionales, de la estética corporal; permiten avizorar, que más allá de la eliminación del estigma, es una reconfiguración de éste, por formas de optimización, de mejoramiento corporal. Por lo cual el estigma ya no yace en la superficie del cuerpo, según lo ha anunciado Foucault (2007) en «El nacimiento de la Clínica», la superficie del cuerpo, dio paso a la interioridad de sus órganos. Hoy el estigma habitaría en la profundidad más profunda de nuestras células, hormonas y moléculas, por tanto su gestión debe ser a esos niveles.

De lo anterior, este «mercado del estigma» se encontraría hoy en relación a lo que Nikolas Rose denomina la «ética somática», que impone obligaciones, pero también alienta las esperanzas individuales, que se orienta al futuro, pero a la vez, exige la acción individual en el presente. (Rose, 2012, p. 33). La ética somática, asigna un lugar central a la gestión de la propia salud y el propio cuerpo de conformidad con la auto representación. (Rose, 2012, p. 96) Sin embargo, el profundo acento en la responsabilidad individual y la oferta del biocapitalismo de suplir nuestras mas profundas necesidades de «eliminación» y «gestión» de nuestros estigmas, configurarían el nuevo estatuto del Biopoder contemporáneo.

\section{Conclusiones}

En la década de los '80 los medios de comunicación con base estructurante en un discurso hegemónico, esta vez el de la biomedicina, contribuyen a incluir al cuerpo del SIDA - que representa el terror del contagio 
homosexual - en el cuerpo terrorista, el gran enemigo interno de la dictadura. Este cuerpo sufriente y excluido que insiste en existir, en verse en un modelo que lo niega, que lo invisibiliza, se suma, se une y se hace parte del cuerpo de la resistencia, porque insiste en SER.

El cuerpo del SIDA comienza a ser envilecido a través de los medios de comunicación proclives al régimen dictatorial, tal como se ha hecho con los otros cuerpos que deben ser aniquilados, extinguidos, invisibilizados, con una base en un discurso hegemónico, con prestigio social, con verdades absolutas provenientes de un modelo científico extinto, que niega el poder de la incertidumbre de la ciencia y se instala en el discurso comunicacional de lo cierto, lo verdadero, lo estable, lo sublime, sumándose a las prohibiciones raciales, jurídicas, morales, políticas, religiosas, heteronormativas, en donde la disciplina militar y las armas es su factor aglutinante del poder.

Surge con ello el inicio de la resistencia a la gestión del cuerpo del SIDA. Este se une a todos los cuerpos que conforman el cuerpo terrorista, el cuerpo de los/as excluidos/as, aquellos cuerpos cuya existencia producen terror. Donde el solo hecho de existir es la generación de una potencia desde esta posición devaluada, es la creación de una resistencia material y simbólica, con la propia corporalidad doblemente deteriorada, donde al parecer es imposible su presencia para quienes detentan la dominación masculina.

\section{Agradecimientos}

El presente documento es resultado del Proyecto DIUFRO «El fenómeno del VIH/SIDA, Biopolítica y Tanatopolítica, el caso chileno». Código: DI16-0017. La autora agradece al convenio de desempeño docente de la Universidad Católica de Temuco y FEQUIP2019.

\section{Nota}

${ }^{1}$ El concepto de «SIDA» (Síndrome de Inmunodeficiencia Adquirida) es creado en 27 de Julio de 1982, en el encuentro en Washington, DC, de oficiales federales, investigadores y activistas, nombrando y configurando, así la nueva enfermedad. Ver NIH (2005 b) In Their Own Words, NIH Researchers Recall the Early Years of AIDS, disponible en <http://history.nih.gov/ nihinownwords/docs/page_27.html>

\section{Bibliografía}

Altman, D. (1981). Rare cancer seen in 41 homosexuals - The New York Times. Recuperado de https:// www.nytimes.com/1981/07/03/us/rare-cancer-seen-in-41-homosexuals.htm

(1986). AIDS in the mind of America. Garden City, NY, England: Anchor Press/Doubleday.

Cadahia, L. (2014). Michel Foucault y la gramática del poder y de la libertad. Estudios de Filosofia. Universidad de Antioquia, 49, 33-49. Recuperado de https://aprendeenlinea.udea.edu.co/revistas/index.php/ estudios_de_filosofia/article/view/19429/16385

Deleuze, G., \& Guattari, F. (1985). El anti-Edipo. Capitalismo y esquizofrenia. Barcelona, España:Ediciones Paidos Iberica, S.A.

Dozon, J.-P., \& Fassin, D. (1989). Raison épidémiologique et raisons d’État. Les enjeux socio-politiques du SIDA en Afrique. Sciences Sociales et Santé, 7(1), 21-36. Recuperado de: https://doi.org/10.3406/sosan.1989.1117

Esposito, R. (2005). Immunitas: protección y negación de la vida. Buenos Aires, Argentina:Amorrortu.

(2006). Bíos: biopolítica y filosofía. Mutaciones. Buenos Aires, Argentina: Amorrortu. 
_ _ _ (2009). Biopolítica y Filosofía: (Entrevistado por Vanessa Lemm y Miguel Vatter). Revista de Ciencia Política (Santiago), 29(1). Recuperado de: https://doi.org/10.4067/S0718-090X2009000100007

Fassin, D. (2007). When Bodies Remember: Experience and Politics of AIDS in South Africa. California, USA: University of California Press.

Fassin, D., \& Rechtman, R. (2009). The empire of trauma: An inquiry into the condition of victimhood. NewJersey, USA: Princeton University Press.

Foucault, M. (2005). Historia de la sexualidad. Tomo 1, La voluntad de saber. Buenos Aires, Argentina: Siglo XXI. (2007). El nacimiento de la clínica. Una arqueologia de la mirada médica. Madrid, España: Siglo XXI.

Gilman, S. L. (1987). AIDS and Syphilis: The Iconography of Disease. AIDS: Cultural Analysis/Cultural Activism, 43, 87-107. Recuperado de: https://doi.org/10.2307/3397566

Goffman, E. (2015). Estigma. La identidad deteriorada. Buenos Aires, Argentina: Amorrortu.

Halperin, D. M. (2002). How to do the history of homosexuality. Chicago, USA: The University of Chicago Press. (2007). San Foucault/ : para una hagiografía gay. Buenos Aires, Argentina: Cuenco de Plata.

Haraway, D. (1995). Ciencia, cyborgs y mujeres La reinvencioìn de la naturaleza. Madrid, España: Ediciones Caìtedra.

Lauretis, T. De. (1989). La tecnología del género. Technologies of Gender. Essays on Theory, Film and Fiction, 634. London, UK: Macmillan Press.

Leclerc, A., Fassin, D., Grandjean, H., Kaminski, M., La, E., \& Inserm, D. (2000). Les inégalités sociales de sante. Paris, France: La Découverte.

MMWR. (1982). Opportunistic Infections and Kaposi's Sarcoma among Haitians in the United States. recuperado septiembre 14, 2019. Recuperado de: https://www.cdc.gov/mmwr/preview/mmwrhtml/00001123.htm

NIH. (2005). In Their Own Words. recuperado septiembre 23, 2019. Recuperado de: https://history.nih.gov/ nihinownwords/index.html

Preciado, P. B. (2002). Manifiesto contra-sexual. Madrid, España: Opera Prima.

Rose, N. (2012). Políticas de la vida: biomedicina, poder y subjetividad en el siglo XXI. La Plata, Argentina: UNIPE, Editorial Universitaria.

Sontag, S. (1996). La enfermedad y sus metáforas| El sida y sus metáforas. Madrid, España: Taurus.

Treichler, P. a. (1987). AIDS, homophobia, and biomedical discourse: an epidemic of significantion. AIDS: Cultural Analysis/Cultural Activism, 43(921641848), 31-70. Recuperado de: https://doi.org/10.1080/ 09502388700490221

Turner, B. S. (2008). The body \& society/ : explorations in social theory. New York, USA: SAGE publications Ltd.

Verón, E. (1993). La semiosis social: fragmentos de una teoría de la discursividad. Barcelona, España: Editorial Gedisa.

(2004). Fragmentos de un tejido. Barcelona, España: Gedisa. 
(2013). La semiosis social, 2: ideas, momentos, interpretantes. Buenos Aires, Argentina: Editorial Paidós.

\section{Material de Análisis según orden cronológico}

\section{Corpus de Prensa escrita}

Ministerio de Salud reconoce existencia de cancer gay en Chile. (1984, Agosto 1). La Tercera, p. 12.

Examen sanguineo detectó primer caso de sida en Chile. 1984, Agosto 1). La Tercera, p. 12.

Normas para tratar la inmunodeficiencia. (1984, Agosto 2). El Mercurio, p.11.

SIDA provoca fiebre y baja en peso físico. (1984, Agosto 5). El Mercurio, p.13.

Paciente chileno con SIDA tiene comprometido todo su cuerpo. (1984, Agosto 8) La Tercera, p. 10.

Homosexuales promiscuos estan propensos a contraer síndrome. (1984, Agosto 8)La Tercera, p. 16.

El SIDA no tiene aun importancia en Chile. (1984, Agosto 10) El Mercurio, p. 14

Falleció primer chileno que padecía el temible «cancer gay». (1984, Agosto 23) La Tercera, Portada y p.10.

Murió Paciente de enfermedad «rara».(1984, Agosto 23) Las Ultimas Noticias, Portada y p.12.

Falleció paciente afectado por SIDA. (1984, Agosto 23) El mercurio, p.14

Ministerio de Salud: SIDA no es una amenaza para la comunidad. (1984, Septiembre 1) El Mercurio, p.15. 